\title{
Monitoring of dietary changes by telephone interviews: results from Denmark
}

\author{
Jóhanna Haraldsdóttir $^{1 *}$, Lotte Holm ${ }^{1,2}$, Arne Vernon Astrup ${ }^{1,2}$, Jytte Halkjær ${ }^{1,3}$ and \\ Steen Stender ${ }^{2,4}$ \\ ${ }^{1}$ Research Department of Human Nutrition, Royal Veterinary and Agricultural University, Rolighedsvej 30, DK-1958 \\ Frederiksberg C, Copenhagen, Denmark: ${ }^{2}$ Danish Nutrition Council, Sydmarken 32D, DK-2860 Søborg, \\ Copenhagen, Denmark: ${ }^{3}$ Present address: Institute of Preventive Medicine, Copenhagen University Hospital, Øster \\ Farimagsgade 3-7, DK-1399 Copenhagen K, Denmark: ${ }^{4}$ Gentofte Hospital, Niels Andersensvej 65, DK-2900 \\ Hellerup, Copenhagen, Denmark
}

Submitted 5 January 2001: Accepted 26 March 2001

\begin{abstract}
Objectives: To monitor trends in Danish food habits with respect to selected key elements, from 1995 to 1998 , and to evaluate the appropriateness of the method developed for that purpose.

Design and method: Two cross-sectional population surveys, in 1995 and 1998. Data collection by computer-assisted telephone interviews including 10 food-frequency questions, questions on type of fat used on sandwiches and drinking milk, and check questions on the previous day. Reproducibility was tested in a subgroup $(n=222)$ in the 1998 survey.

Setting: The Danish Nutrition Council initiated the survey.

Subjects: Men and women aged 15-90 years, 1007 in 1995 and 1024 in 1998. Samples of private telephone numbers were drawn from regional telephone registers, geographically stratified. Participation rates were $62 \%$.

Results: Significant differences were observed between 1995 and 1998, some of these in accordance with dietary guidelines (decreased use of whole milk and fat spread on bread, increased use of skimmed milk, salad vegetables, rice/pasta and fish). Other changes were opposite to dietary guidelines (increased use of soft butter, decreased use of soft margarine and low-fat spreads, potatoes, and fresh fruit). Differences in average consumption frequency amounted to 4-13\%. Several results were confirmed by comparison with other data, and the reproducibility of the method was acceptable. Data were suitable for analysis of food use patterns, a relevant approach when assessing food habits in a lifestyle context.

Conclusions: The changes observed illustrate the dynamics of food habits and the need for frequent monitoring. This simple telephone method may be a valuable tool for that purpose, as a supplement to national dietary surveys, also in a public health context.
\end{abstract}

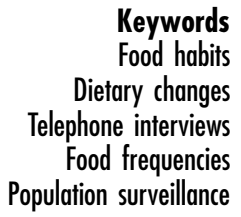

Dietary habits are in a constant process of change. Public health authorities, food authorities, the food industry and others working within this field need up-to-date data on the dietary habits of the population as a basis for their initiatives. Up until now the availability of such data has been limited in Denmark. Only two national dietary surveys have been carried out, in 1985 and $1995^{1-4}$, i.e. with an interval of 10 years. Food Balance Sheets (statistical information on the amount of different foods available for consumption per capita, per year) have therefore been an important source of annual data ${ }^{5}$. In spite of the shortcomings of that type of information, the
Danish food balance sheets have been most useful for monitoring long-term trends in the consumption of different foods ${ }^{6}$. This was, however, no longer the case in the beginning of the 1990s as several important food groups were no longer included in these official statistics (fruit, vegetables, fish).

In 1995 the Danish Nutrition Council, which needs upto-date data on a regular basis, therefore decided to start a quick and simple data collection every two to three years, covering selected aspects of food intake. The aim was to supplement the national dietary surveys and the food balance sheets with intake data on certain foods that are 
key elements in the Danish diet, and which are suitable for comparison with food-based dietary guidelines. Consequently it was decided that data should be analysed on the food level only, without any nutrient calculations, and that the data should be collected in a manner which reflected everyday use of these foods. The first survey was carried out in 1995 , the second in $1998^{7,8}$.

This paper compares the results of the two surveys and evaluates the results. The main aim is to discuss the relevance of this data collection method, in particular whether it is appropriate for detecting changes in intake. Another aim is to discuss the changes observed and their nutritional implications.

\section{Material and methods}

\section{Subjects}

Participants were adult men and women aged 15-90 years, 1007 in 1995 (461 men, 546 women) and 1024 in 1998 (491 men, 533 women). Two separate samples were drawn, one in 1995 and one in 1998, as samples of private telephone numbers from regional telephone registers stratified according to geographical distribution. The original sample of phone numbers was reduced owing to numbers that had been closed down and other technical reasons, resulting in a net sample of 1624 in 1995 and 1642 in 1998. In 1995 the participation rate was $62 \%, 21 \%$ were not at home (three attempts were made) and $17 \%$ did not want to participate. In 1998 the corresponding figures were 62\% participation, 14\% not at home and $24 \%$ did not want to participate. Only one person per household (= phone number) was interviewed, selected so as to achieve a representative age and sex distribution in the sample. This was done by regularly asking for someone else from the household instead of the person answering the phone, for instance specifically asking for the youngest male in the household (15+ years) at regular intervals.

Information on the following background variables was collected, as a supplement to the dietary data: age, education, employment, marital status, number of children and size of household.

\section{Food intake}

Data were collected by a computer-assisted telephone interview (CATI). The core of the interview consisted of food-frequency questions on 10 selected foods: potatoes, rice/pasta, cooked vegetables, green salad/shredded vegetables, fruit, meat as a main meal, fish as a main meal, fish with sandwiches, drinking milk, yoghurt. These foods were selected because they are all included in the Danish food-based dietary guideline. In addition to this core there were questions on the type of milk and the type of fat spread used on bread. In the last part of the interview respondents were asked whether they had consumed any of these foods the previous day. The number of foods included was increased from 10 to 13 in the 1998 survey (additions: cheese, rye bread, wheat bread).

For the frequency questions the following categories were used: never/seldom, less than once per week, once per week, a couple of times per week, almost every day, every day, several times per day. Other answers such as 'do not know' were not accepted.

Data were collected in the early autumn by a market analysis company (Vilstrup A/S) and their 25 telephone interviewers. In 1995 this was in the last week of September whereas in 1998 the collection period had to be changed to the middle of August due to the introduction of a new '6-a-day' initiative on fruit and vegetables early in September.

\section{Reproducibility test}

In the 1998 survey the reproducibility of the dietary data was tested in a subgroup $(n=222)$ by repeating the interview a week later. A random sample $(n=270)$ was drawn from the total respondent group $(n=1024)$ in the main survey. Participation rate was $82 \%$ (17\% were not at home, 1\% did not want to participate). Among the 222 respondents there were $47 \%$ men and $53 \%$ women; the distribution between the age groups was: 10\% (15-24 years), 35\% (25-39 years), 30\% (40-59 years), 25\% (60+ years).

\section{Data analysis}

Food-frequency results were first analysed according to original frequency categories. For simple comparisons between the results of 1995 and 1998, these categories were also translated into absolute frequencies (times per week): never/seldom $=0.0$, less than once per week $=0.5$, once per week $=1.0$, a couple of times per week $=2.5$, almost every day $=5.5$, every day (and several times per day) $=7.0$. Based on these translations a group average frequency was calculated for each food. Frequency differences between the two years, and between men and women, were tested by comparing average frequencies using a non-parametric test (MannWhitney $U$-test) or by comparing frequency distributions using a chi-square test. The statistical package SPSS was used to analyse the data.

\section{Results}

Participation rate was 62.0\% in 1995 and 62.4\% in 1998. The two samples were relatively close to being representative of the Danish population with respect to sex, age and geographical distribution (Table 1). The two samples were comparable with respect to socio-economic background, but compared with the general population both samples included a somewhat lower proportion of subjects with low socio-economic status. For example, 
Table 1 Characteristics of respondents in the two surveys compared with the total population of Denmark

\begin{tabular}{|c|c|c|c|}
\hline & $\begin{array}{c}1995 \text { survey } \\
\text { (15-90 years) } n=1007 \text { (\%) }\end{array}$ & $\begin{array}{c}1998 \text { survey } \\
\text { (15-90 years) } n=1024 \text { (\%) }\end{array}$ & $\begin{array}{c}\text { Total adult population } \\
\text { (16+ years) }(\%)\end{array}$ \\
\hline \multicolumn{4}{|l|}{ Sex } \\
\hline Men & 45.8 & 47.9 & 48.9 \\
\hline Women & 54.2 & 52.1 & 51.1 \\
\hline \multicolumn{4}{|l|}{ Age } \\
\hline $15-24$ years & 12.7 & 15.2 & 14.5 \\
\hline $25-39$ years & 30.2 & 33.4 & 27.9 \\
\hline $40-59$ years & 33.2 & 30.7 & 33.5 \\
\hline $60+$ years & 23.9 & 20.7 & 24.1 \\
\hline \multicolumn{4}{|l|}{ Geographical distribution } \\
\hline Jutland & 46.0 & 48.4 & 46.4 \\
\hline Greater Copenhagen region & 29.0 & 30.7 & 33.3 \\
\hline Other regions & 25.0 & 20.9 & 20.3 \\
\hline
\end{tabular}

$39 \%$ of participants only had basic education ( 9 years in school) versus $46 \%$ in the general population.

Comparison of results from the two surveys showed several differences. First, in 1998, it had become more common to cut down on fat by skipping fat spreads on bread, or by choosing skimmed or semi-skimmed milk instead of full-fat milk. Thus almost 30\% did not use fat spread on rye bread (the traditional Danish bread) and $16 \%$ did not use it on wheat bread (Fig. 1). However, among those who did use fat, the type of spread changed, for rye bread in particular. The use of soft butter (typically containing $3 / 4$ butter fat, $1 / 4$ vegetable fat) increased substantially at the expense of soft margarine and low-fat spreads, so that for rye bread the ratio of butter users to margarine users increased from 53:46 (\%) in 1995 to 70:29 (\%) in 1998 (Table 2). Soft butter is now the most common fat spread, followed by butter, whereas soft margarine and low-fat spreads are much less common. In order to investigate this further we also collected sales statistics directly from the Danish margarine industry and supermarket suppliers, covering the period 1990-1995/ 97. Figure 2, which includes all separated fats - i.e. also fats used in cooking, shows an increasing amount of soft
Table 2 Type of fat spread on bread

\begin{tabular}{lcc}
\hline & \multicolumn{2}{c}{$\%$ of fat spread users } \\
\cline { 2 - 3 } & 1995 & 1998 \\
\hline On rye bread & & \\
$\quad$ Soft butter & 35 & 49 \\
Butter & 18 & 21 \\
Margarine & 28 & 14 \\
$\quad$ Low-fat spread & 18 & 15 \\
On wheat bread† & 53 & \\
Soft butter & 29 & 58 \\
Butter & 9 & 29 \\
Margarine & 8 & 6 \\
Low-fat spread & & 6 \\
\hline
\end{tabular}

* Excluding non-users of fat spread on rye bread $(22 \%$ in $1995,28 \%$ in 1998).

† Excluding non-users of fat spread on wheat bread (12\% in $1995,16 \%$ in 1998).

$\ddagger$ Soft butter products typically contain $3 / 4$ butter fat and 1/4 vegetable fat.

butter and a decreasing amount of margarine during this period.

In 1998 skimmed and semi-skimmed milk had become more common than in 1995, and full-fat milk less common (Fig. 3). These differences for skimmed and full-fat milk also remained significant after adjustment for

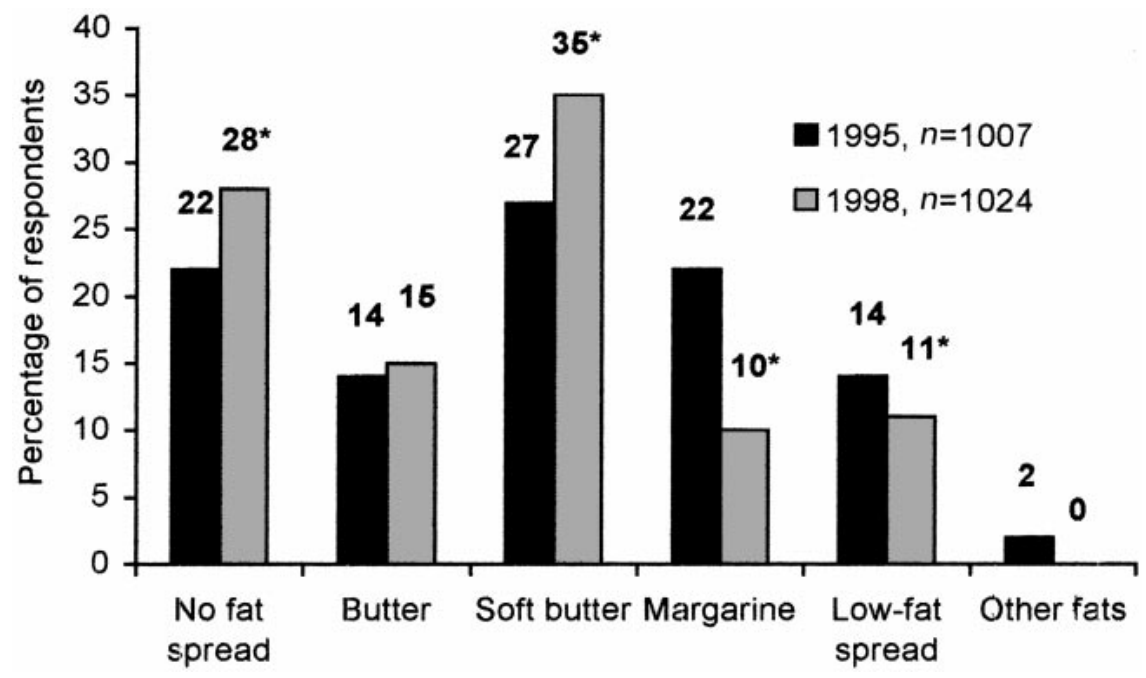

Fig. 1 Fat spreads on rye bread; comparison between 1995 and $1998\left({ }^{*}\right.$ denotes significantly different from the 1995 value $\left.(P<0.05)\right)$ 

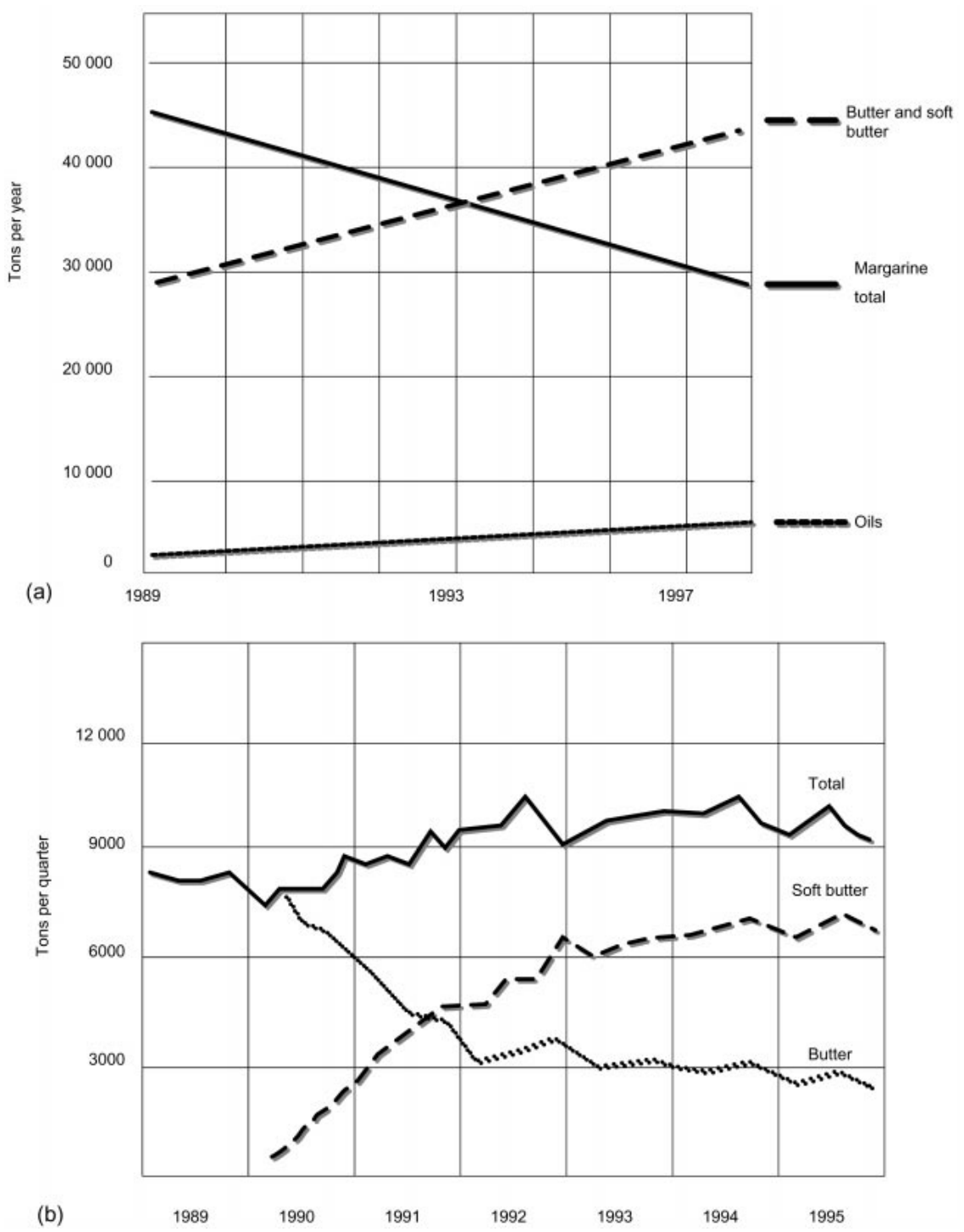

Fig. 2 Sales of separated fats in Denmark 1989-97: (a) annual sales of separated fats 1989-97; (b) quarterly sales of soft butter and butter 1989-95. Data on sales of margarine and oils were kindly supplied by the Danish Margarine Industry Organisation. Data on sales of butter were derived from the Danish food balance sheets and combined with quarterly data on relative sales of butter and soft butter, which were kindly supplied by the Cooperative Organisation (FDB) and the Organisation of Danish Supermarkets (Dansk Supermarked A/S). These two companies' supermarket outlets covered $60-75 \%$ of the total sales of separated fats in Denmark in this period

answers in the category 'more than one type of milk', a type of answer only accepted in the 1995 survey (Fig. 3). Semi-skimmed milk (1.5\% fat) is the most common type of milk in Denmark, consumed by more than half of the milk consumers in this age group.

Food-frequency results showed significant differences between the two surveys for several foods. Increased average frequency was observed for vegetables in the form of salad/shredded vegetables, for rice/pasta and for fish as a main meal, whereas average frequency decreased for potatoes, for meat as a main meal and for fresh fruit (Table 3). These differences amounted to 4$13 \%$ of the average. The largest difference, 0.4 times per week, was observed for salad and meat $(+13 \%$ and $-8 \%$, respectively) followed by rice/pasta and potatoes at 0.3 times per week $(+13 \%$ and $-7 \%$, respectively). For fish the absolute difference was very small, 0.1 times per week $(+11 \%)$, and for fruit it was 0.2 times per week $(-4 \%)$. No significant difference was observed for cooked vegetables, milk, yoghurt or fish with sandwiches. Separate analysis for men and women demonstrated that differences were larger for women than for men, and that men showed significant differences for only two foods (meat and rice/pasta) although their non-significant trends pointed in the same direction as for the women.

The internal validity of the frequency results was estimated by comparison with the data on yesterday's intake collected in the second part of the interview (see 


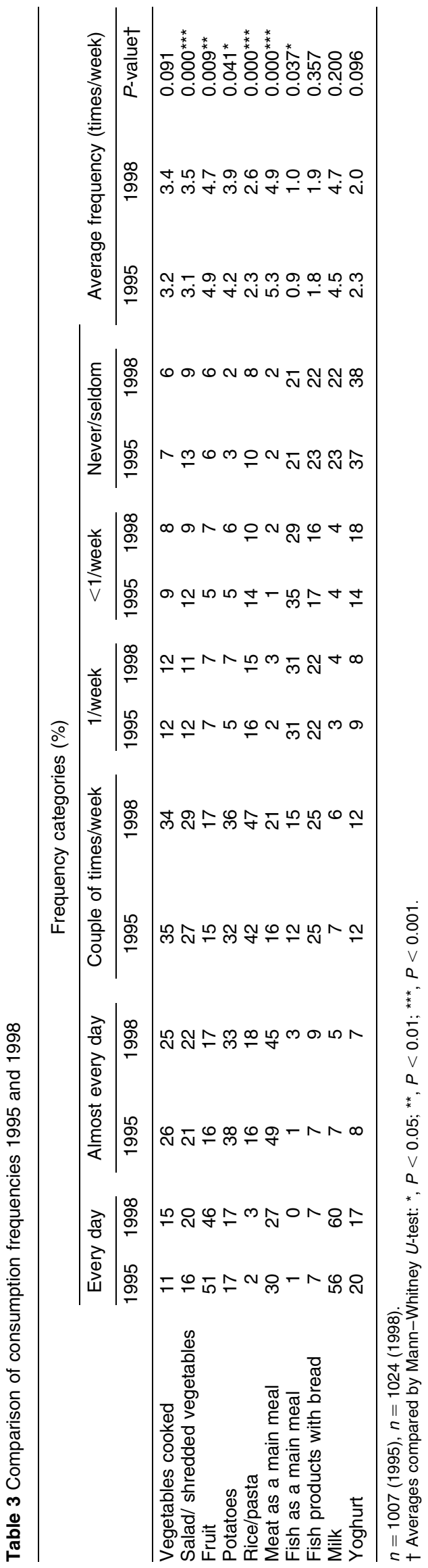

Table 4 Reproducibility test $(n=222)$. Cross-classification of answers from first and second interview* into response categories

\begin{tabular}{|c|c|c|}
\hline & \multicolumn{2}{|c|}{ Response category } \\
\hline & Same (\%) & Same $\pm 1(\%)$ \\
\hline \multicolumn{3}{|l|}{ Frequency questions† } \\
\hline Vegetables, cooked & 48 & 78 \\
\hline Salad/shredded vegetables & 39 & 81 \\
\hline Fruit & 60 & 85 \\
\hline Potatoes & 57 & 96 \\
\hline Rice/pasta & 55 & 91 \\
\hline Meat as a main meal & 56 & 96 \\
\hline Fish as a main meal & 55 & 94 \\
\hline Fish products with bread & 43 & 82 \\
\hline Milk & 80 & 87 \\
\hline Yoghurt & 56 & 84 \\
\hline Cheese & 74 & 95 \\
\hline Rye bread & 86 & 97 \\
\hline Wheat bread & 63 & 83 \\
\hline Average & 59 & 88 \\
\hline \multicolumn{3}{|l|}{ Additional questions } \\
\hline Type of milk $\ddagger$ & 93 & - \\
\hline \multicolumn{3}{|l|}{ Type of fat spread§ } \\
\hline On rye bread & 79 & - \\
\hline On wheat bread & 73 & - \\
\hline
\end{tabular}

* One week interval between first and second interview.

$\dagger$ Number of response categories $=6$.

$\ddagger$ Number of response categories $=4$.

$\S$ Number of response categories $=5$.

Methods). Between 70 and $92 \%$ of subjects who reported eating a certain food 'every day' also reported to have consumed that food the day before (highest value for fruit, lowest value for cooked vegetables, results not shown). Further, there was a positive relationship between the frequency category and the proportion of yesterday consumers, as shown for two examples in Fig. 4.

The reproducibility of the dietary data was tested in a subgroup $(n=222)$ in 1998 by repeating the interview a week later. The second interview included the frequency, milk and fat spread questions. Cross-classification of frequency answers from the two interviews showed that for all foods in total almost $60 \%$ of subjects gave identical answers in both interviews, ranging from 39\% to $86 \%$ for the individual foods. When the neighbouring categories were included, almost $90 \%$ gave either identical or neighbour-category answers (range 78-97\%) (Table 4). For the questions on the type of fat spread and the type of milk used, identical answers were given in both interviews by $73-93 \%$ of subjects (Table 4 ). The reproducibility test also revealed that although the average group frequencies were similar in the first and the second interview for 10 of the 13 foods tested, three foods showed systematically lower average in the second interview (salad/shredded vegetables, cooked vegetables, rice/pasta). These differences amounted to 0.2-0.5 times per week (lowest for rice/pasta, highest for salad/ shredded vegetables, $P$-values $0.043-0.000$, respectively). 


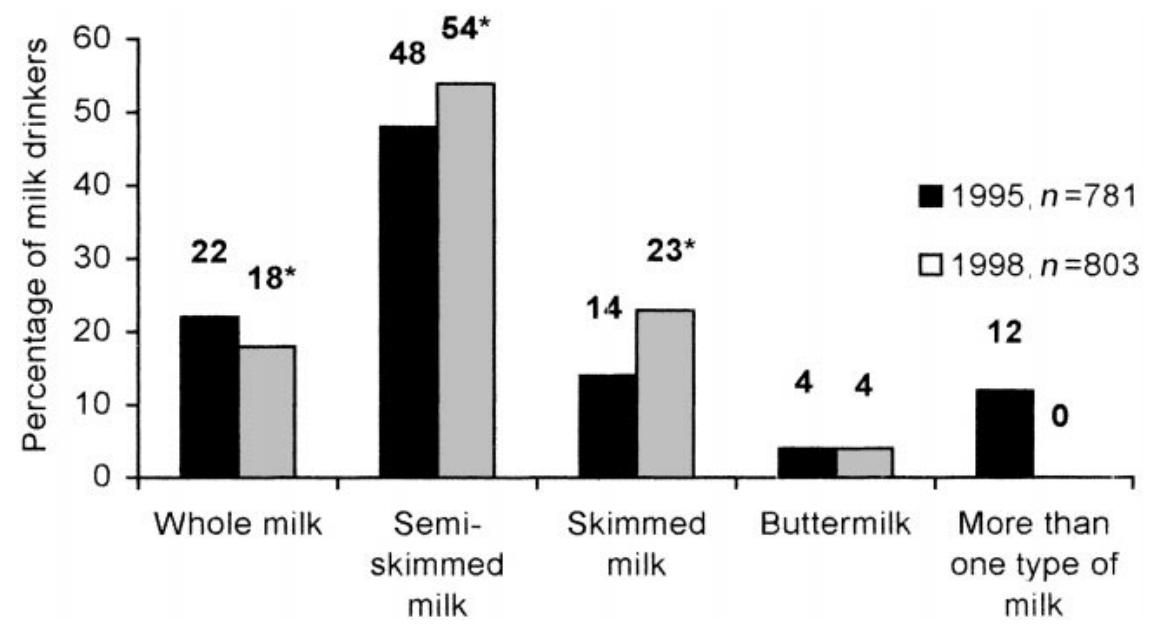

Fig. 3 Type of milk; comparison between 1995 and $1998\left({ }^{*}\right.$ denotes significantly different from the 1995 value $\left.(P<0.05)\right)$. The answer 'more than one type of milk' was accepted only in the 1995 survey. For results of adjustments for this category, see text

\section{Discussion}

The results of these two surveys indicate that several changes in food habits have occurred during the three-year period 1995-1998. Some of these findings can be confirmed by food balance sheets or other available data for the same time period. Thus the increased use of skimmed milk at the expense of whole milk is also
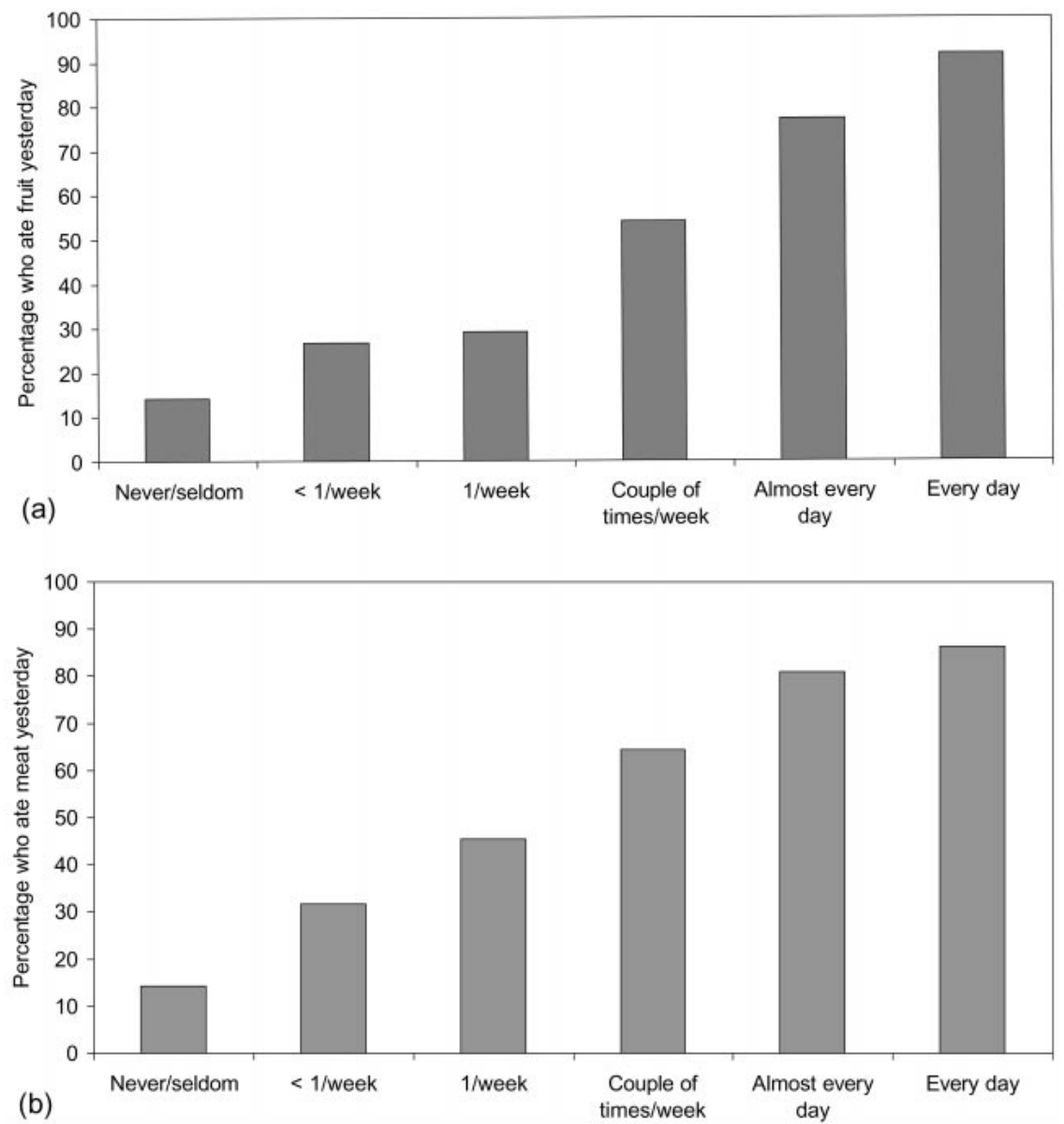

Fig. 4 Comparison between frequency answers and the previous day's intake: (a) fruit - proportion of respondents within the different frequency categories who had eaten fruit the previous day; (b) meat - proportion of respondents within the different frequency categories who had eaten meat the previous day 
demonstrated by production statistics from the dairy industry ${ }^{9}$. The observed decrease in use of margarine and increase in rice and pasta is supported by food balance sheets, although less directly for pasta than for rice ${ }^{10}$. As soft butter is not included in the food balance sheets or other official statistics the observed increase cannot be compared to such data, but the results are clearly supported by the collected sales statistics presented here (see Results). The less frequent use of meat as a main meal observed in the present study is not supported by food balance sheets, which show no long-term downward trend for total 'meat and meat product' consumption, and the annual figures fluctuate too much to evaluate a three-year period ${ }^{10}$. Neither is the observed decrease in use of potatoes confirmed by the food balance sheets, which have presented a constant amount for several years ${ }^{10}$. For fish, which is not included in the food balance sheets, the slight increase observed between 1995 and 1998 coincided with a long-term campaign for increasing fish intake, including a regular TV spot on the main television channel. According to the fish trade, the campaign had a noticeable positive effect on the sale. The changes observed with respect to fruit and vegetable intake cannot be compared with other data, as fruit and vegetables are no longer included in the Danish food balance sheets and suitable sales statistics are not available. However, it is possible that the decline reported in fruit intake was influenced by the fact that in 1998 data had to be collected a month earlier than in 1995 , i.e. mid-August instead of the end of September (due to the start of a nation-wide ' 6 -a-day, eat more fruit and vegetable' initiative at the beginning of September 1998). This time difference may have caused a bias towards a lower consumption in the 1998 survey as the peak season for Danish apples and pears starts in September. At present no suitable data on seasonal variation in fruit intake are available for clarifying that question.

The increase in non-use of fat spread observed in the 1998 survey seems to be a continuation of a steady trend since 1985 . At that time only $7 \%$ reported not using fat spread on rye bread $^{4}$, in 1991 this proportion had increased to $15 \%$ and in 1995 to $21 \%^{2}$, and the present studies showed $22 \%$ in 1995 and $28 \%$ in 1998. Two of these figures are based on quantitative dietary surveys (the $7 \%$ in $1985^{4}$ and the $21 \%$ in $1995^{2}$ ) using dietary history interviews and 7-day food records, respectively. This trend seems to be a reflection of health campaigns during this same period that have focused heavily on reduction of fat intake, with particular emphasis on fat on bread and fat used in cooking. Parallel to this there has been an increased marketing of fat-reduced products such as low-fat dairy products. This focus on fat has at times been so massive that 'less-fat' could appear to be synonymous with a healthy diet.

From a nutritional point of view, it is an important, positive change that more people cut down on fat by using no fat spread on bread or by drinking skimmed or semi-skimmed milk instead of whole milk. Fat spread on bread is one of the largest fat sources in the Danish diet, where $40 \%$ of total fat intake comes from separated fats (used on bread and in cooking) ${ }^{1}$, and dietary guidelines therefore encourage the population to reduce fat on bread. However, another important change, which is negative from a nutritional point of view, is the change in type of fat spread used, with butter fat in the form of soft butter substituting soft margarine and low-fat spreads. This change implies more saturated fatty acids and less polyunsaturated fatty acids (as soft butter typically contains $40 \%$ saturated and $8 \%$ polyunsaturated fatty acids, compared with 16\% saturated and 44\% polyunsaturated fatty acids in soft margarine ${ }^{11}$ ). This is a change in the opposite direction of nutritional recommendations of maximum $10 \mathrm{E} \%$ saturated fatty acids ${ }^{12}$ as compared with the average intake in Denmark of $15 \mathrm{E} \%{ }^{1}$. The more frequent intake of vegetables observed in 1998, in particular among women, represents a step in the right direction compared with dietary guidelines. However, there is a long way to go to fulfil the Danish recommendation of $600 \mathrm{~g}$ of fruit and vegetables every day (potatoes not included) ${ }^{13}$, as only $28 \%$ of respondents consumed some type of vegetable every day ${ }^{8}$. In contrast to vegetables, the use of fresh fruit seemed to have moved in a negative direction, but, as discussed above, the results may have been biased by the data collection period. For meat and fish the results indicated a slight change in the all-dominating role of meat as the centre of hot meals. The less frequent use of meat, mainly due to a reduction in the number of everyday consumers, was observed for men as well as women, whereas the increased use of fish was significant only for women. Even so, more than $70 \%$ reported eating meat with a hot meal 'every day' or 'almost every day', whereas only 18\% had fish with a hot meal more than once per week.

When interpreting the observed differences in average consumption frequency between the two surveys it should be borne in mind that their basis is frequency categories that were translated into absolute numbers (see Data analysis). Meaningful differences would, no doubt, be those of 0.3 or 0.4 times per week, equivalent to $13 \%$ of the average, as observed for salad and rice/pasta, whereas a difference of only 0.1 times per week, as observed for fish, has to be interpreted more cautiously, although statistically significant and equivalent to $11 \%$ of the average frequency.

The present surveillance of food habits was set up as a simple system based on food frequencies and supplementary questions about milk and fat. The questions were designed to capture key elements of the Danish diet and to be comparable with dietary guidelines. They therefore focused on important sources of fat in the Danish diet and on foods that are included in the Danish dietary guidelines. The way foods are combined into dishes and meals varies according to countries and cultures. The concepts 
and formats through which individuals reflect and understand foods in everyday life may be inconsistent with the way foods are seen from a nutritional point of view $^{14}$. Therefore, attempts were made to pose the foodfrequency questions in a manner that reflected Danish cultural patterns of food combinations. In Denmark hot meal formats are often similar to what has been described as the British meal format ${ }^{15}$, but cold meals consisting of open sandwiches is an important meal format too, in particular for lunch. Accordingly, it was in some cases considered necessary to distinguish between the use of foods with hot and cold meals. An example is fish which in Denmark may be eaten as a hot main meal, but fish products are also frequently eaten with bread as part of a cold sandwich meal (e.g. pickled herring, tinned mackerel, tinned cod roe). Instead of a single question on 'fish' we therefore split it up into two questions ('fish as a main meal' and 'fish products with bread') in order to explicitly remind respondents of these two contexts.

Simplicity was a characteristic feature of the method developed for this monitoring purpose. First, data were collected through computer-assisted telephone interviews, which implies that data files are ready for analysis a couple of days after data collection has been completed. Secondly, relatively few foods were included and data were only analysed in terms of frequencies. In spite of this simplicity the results showed similar intake differences between men and women, and between age groups, as have been reported from traditional, quantitative dietary surveys in Denmark ${ }^{7,8}$. This indicates that, for most of these foods, frequency of consumption is the key factor in determining intake. For other foods, such as bread and meat, consumption frequency variation between individuals is small and portion size information therefore becomes more important. An important consequence of the simplicity of the data collection method is that it has a number of inherent limitations. First of all it covers a only limited part of the diet, a list of foods selected for a particular purpose, and it cannot therefore give any information on the macronutrient composition of the diet or the nutrient intake. For example, it cannot be assumed that subjects who only use skimmed milk and no fat on bread have a more lean diet overall than others, as they may well have a high fat intake from other sources. Secondly, the list of foods selected specifically for the present context may not be equally relevant for other purposes. Finally, a higher consumption frequency cannot automatically be translated into a higher intake in terms of grams per day, as intake depends on frequency as well as portion size. These limitations should be borne in mind when this type of simple data is used.

The reproducibility test results, showing that the large majority of subjects gave reasonably consistent answers, indicate that subjects did not answer the food-frequency questions at random, and this was supported by comparison with data on the previous day's intake. The same holds for the questions on the type of fat and the type of milk used, where even more subjects gave completely identical answers on both occasions. In the present surveillance system, where a new sample is drawn for every survey, the reproducibility of the answers is not essential in itself. Accordingly, a difference in group means between the first and second interviews, as was observed for three of the 13 foods included in the present study, does not have any implications in this context, in contrast to surveys based on repeated measurements on the same individuals where such a bias would be a serious obstacle. Reproducibility studies in the literature confirm the present finding that if a systematic difference between the first and the second administration of foodfrequency questions is observed, then the lowest mean value is usually obtained from the second interview ${ }^{16-18}$. This raises the question of the respondents' understanding and thinking when answering such food-frequency questions, and we have recently investigated this aspect of the questions by the use of focus group discussions.

This presentation of the results has focused on the comparison between the two surveys. However, the collected data are also suitable for a number of other analyses, due to the simplicity of the data. One example is analyses of food combinations, e.g. whether subjects who report never eating fish as a main meal do regularly eat fish products with bread ${ }^{7}$. Another example is analyses of food patterns, e.g. whether subjects not using any fat spread on bread have a more frequent intake of certain foods such as fruit, vegetables and fish ${ }^{19}$. Such analyses throw light on other dimensions of food intake than do traditional surveys, as they describe food intake as eating occasions rather than solely as average daily amounts (grams per day). This type of information is a good basis for understanding food habits in a way that is closer to the cultural eating practices of the population. It is therefore highly relevant when assessing food habits as part of a 'lifestyle' pattern, as often is the case in a public health context. Traditional dietary surveys are usually difficult to analyse in this way, as data are most often merged at an early stage in the analytical process. The costs of this type of survey are modest compared with those of traditional dietary surveys. For example, a simple repetition of the 1998 survey, including 1000 respondents, would require the equivalent of $£ 6000-7000$ sterling for data collection, plus approximately two man months for analysis and reporting of the results.

In a monitoring system the representability of the population sample and the comparability of the samples from one measurement year to the next are important aspects. In the present surveys the two samples differed slightly but corrections for age and sex differences showed a negligible impact on mean frequencies $(\leq 0.1$ times per week) and did not affect significant differences observed between the 1995 and 1998 survey results. The 
slight differences in socio-economic variables between the two samples were not systematic and they were therefore unlikely to have any impact on the observed results. Within age-sex groups the comparability of the samples is limited by the smaller sample size, and comparisons of results within age groups therefore have to be interpreted more cautiously than for the total sample. The sampling frame used in the two surveys was regional telephone registers, and the resulting samples were relatively representative of the general population with respect to sex, age and geography. However, with the rapidly growing mobile phone market in Denmark using phone cards instead of telephone subscription, this sampling frame may need to be reconsidered before the next survey.

\section{Conclusions}

The rapid changes occurring in the three-year period 19951998 for some food categories illustrate the dynamics of food habits and the need for frequent monitoring of food intake trends. The simple telephone method developed for this purpose was able to detect changes in the intake of some key elements in the Danish diet, and at the same time it produced a type of food habit data that is particularly relevant in a lifestyle assessment context. This approach therefore seems to be a valuable tool for monitoring purposes, as a supplement to traditional national dietary surveys, also in a public health context.

\section{References}

1 Andersen NL, Fagt S, Groth MV, Hartkopp HB, Møller A, Ovesen L, Warming DL. Danish Dietary Habits 1995, Main Results [in Danish with an English summary]. Publ. No. 235. Copenhagen: Levnedsmiddelstyrelsen (National Food Agency), 1996.

2 Fagt S, Groth MV, Andersen NL. Danish Dietary Habits 1995, Foods and Meals [in Danish with an English summary]. FødevareRapport 2000:06. Copenhagen: Fødevaredirektoratet (Danish Food Administration), 2000.

3 Haraldsdóttir J, Holm L, Jensen JH, Møller A. Dietary Habits in Denmark 1985. 1. Main Results [in Danish with an English summary]. Publ. No. 136. Copenhagen: Levnedsmiddelstyrelsen (National Food Agency), 1986.
4 Haraldsdóttir J, Holm L, Jensen JH, Møller A. Dietary Habits in Denmark 1985. 2. Who Eats What? [in Danish with an English summary]. Publ. No. 154. Copenhagen: Levnedsmiddelstyrelsen (National Food Agency), 1987.

5 Danmarks Statistik. Statistical Yearbook 1998. Copenhagen: Danmarks Statistik, 1999.

6 Fagt S, Groth MV. Development of Food Consumption in Denmark 1955-1990; Description of the Danish Diet Based on Food Statistics and Nutrition Calculated Data [in Danish with an English summary]. Publ. No. 214. Copenhagen: Levnedsmiddelstyrelsen (National Food Agency), 1992.

7 Haraldsdóttir J, Holm L, Jensen H. Surveillance of food consumption using telephone interviews [in Danish with an English summary]. Ugeskr Lager 1996; 158: 7402-6.

8 Haraldsdóttir J, Halkjær J, Holm L, Stender S, Astrup AV. Changes in Danish food habits from 1995 to 1998 [in Danish with an English summary]. Ugeskr Loeger 1999; 161: 502833.

9 Mejeriforeningen (Danish Dairy Board). Mejeristatistik [Dairy Statistics]. Århus: Mejeriforeningen, 1999.

10 Danmarks Statistik. Statistical Yearbook 1999. Copenhagen: Danmarks Statistik, 2000.

11 Møller A, Saxholt E. Levnedsmiddeltabeller [Food Composition Tables], 4th ed. Copenhagen: Levnedsmiddelstyrelsen (National Food Agency), 1996.

12 Nordiska Ministerrådet (Nordic Council of Ministers). Nordiska Näringsrekommendationer 1996 [Nordic Nutrient Recommendations, in Swedish]. Nord 1996:28. Copenhagen: Nordisk Ministerråd, 1996.

13 Trolle E, Fagt S, Ovesen L, eds. Fruit and Vegetables, Recommendations for Intake [in Danish]. Publ. No. 244. Copenhagen: Veterinær og Fødevaredirektoratet (Danish Veterinary and Food Administration), 1998.

14 Holm L. Cultural and social acceptability of a healthy diet. Eur. J. Clin. Nutr. 1993; 47: 592-9.

15 Douglas M, Nicod M. Taking the biscuit: the structure of British meals. New Society 1974; 19: 744-7.

16 Rockett HRH, Wolf AM, Colditz GA. Development and reproducibility of a food frequency questionnaire to assess diet of older children and adolescents. J. Am. Diet. Assoc. 1995; 95: 336-40.

17 Bohlscheid-Thomas S, Hoting I, Boeing H, Wahrendorf J. Reproducibility and relative validity of food group intake in a food frequency questionnaire developed for the German part of the EPIC project. Int.J. Epidemiol. 1997; 26(Suppl. 1): S5970.

18 van Liere MJ, Lucas F, Clavel F, Slimani N, Velleminot S. Relative validity and reproducibility of a French dietary history questionnaire. Int. J. Epidemiol. 1997; 26(Suppl. 1): S128-36.

19 Haraldsdóttir J, Jensen H, Holm L, Astrup A. No fat on bread - an indicator of healthy eating habits? Scand.J. Nutr. 2000; 44(Suppl. 2): S108 